\title{
Basal Ganglionic Lesions in Egyptian Children:Radiological Findings in Correlation with Etiology and Clinical Manifestations
}

Hamada I Zehry $^{1 *}$,Shora Y Darwish ${ }^{1}$, Sayed A El zayat ${ }^{1}$, Mohamed F Abdelmotey ${ }^{2}$, Hassan K Gad ${ }^{1}$, Hossam M Emam ${ }^{1}$, Mohie El din T Mohamed ${ }^{1}$

\author{
${ }^{1}$ Departments of Neurology, AlAzhar University, Cairo, Egypt \\ ${ }^{1,2}$ Faculty of Medicine, AlAzhar University, Cairo, Egypt \\ ${ }^{2}$ Radiology, AlAzhar University, Cairo, Egypt
}

\author{
Correspondence author \\ Hamada Ibrahim Zehry \\ Department of Neurology \\ Faculty of Medicine \\ AlAzhar University \\ Egypt \\ Mobile : +201091949392 \\ E-mail : zehryhamada@yahoo.com
}

Submitted : 6 Mar 2020 ; Published : 16 Mar 2020

\begin{abstract}
Background: In childhood, the metabolic activity of the basal ganglia is greater and they are particularly prone to injury. The lesions may be unilateral: in Rassmussen encephalitis or - more frequently - bilateral in many pathologic conditions like Carbon monoxide poisoning, hypoglycemia, and Wilson disease. Damage to the basal ganglia cells may cause problems controlling speech, movement, consciousness, muscle tone, posture and cognition.

Aim of the Study: to determine the etiology of basal ganglionic disorders in a sample of Egyptian children.

Methods: This study was conducted on 34 patients attended the Pediatric Neurology of AlAzhar University Hospitals during a period of one year from the beginning of November 2014 to the end of November 2015. A specialized pediatric neurological sheet, Cognitive assessment in children using Stanford Binet Intelligence Scale and Laboratory investigations were performed.

Results: Acute ischemic stroke was the most frequent cause, which was found in 12 (35.3\%) cases, followed by 10 (29.4\%) had metabolic and infectious causes, and lastly $2(5.9 \%)$ had toxic causes. The incidence of toxic causes (CO poisoning) was significantly higher among ganglionic group compared to paraganglionic group (8.7\% versus $0.0 \%$, respectively).

Conclusion: Acute ischemic stroke was the most frequent cause of basal ganglionic lesion in a sample of Egyptian children.
\end{abstract}

Keywords: Para ganglionic lesions, ischemic stroke, a sample, metabolic disorders.

\section{Introduction}

The basal ganglia consist of a group of related subcortical nuclei, which, together, are responsible for multiple brain functions. Primarily, the function of the basal ganglia is to control and regulate volitional movement to ensure smooth performance. However, there are multiple other functions of the basal ganglia, including procedural learning, behaviors, and contributions to cognition and emotion. Anatomically, the basal ganglia are composed of several nuclei: the striatum (consisting of the caudate nucleus, putamen, and nucleus accumbens), the GP, the SN, and the STN. Functionally, the basal ganglia have considerable connections to the cerebral cortex, thalamus, and brain stem; in fact, anatomists consider portions of the thalamus as components of the basal ganglia [1].
The basal ganglia are a site of high adenosine triphosphate (ATP) production and thus require a relatively disproportionate increased blood supply. Consequently, bilateral basal ganglia alterations are often observed in pathological processes affecting energy metabolism. A complete differential diagnosis of systemic and metabolic diseases would be exhaustive; therefore, understanding of the underlying pathology and imaging findings is critical for final diagnosis, treatment, and prognosis [2].

Both acute and progressive disorders can result in bilateral symmetrical basal ganglia alterations. Primary acute causes include hypoxicischemic injury, infection, autoimmune disorders, and toxic encephalopathies. Subacute or progressive pathologies 
are usually neurodegenerative and/or metabolic in nature. The pediatric population (here defined as ages 22 days to 18 years) presents unique diagnostic dilemmas, since many metabolic and genetic disorders often initially present during this time period. Identification of patterns of involvement of specific gray and/or white matter structures may aid in diagnosis [3].

\section{Aim of the Work}

The aim of this work is to determine the etiology of basal ganglionic disorders in a sample of Egyptian children.

\section{Patients and Methods}

The present study included all children presented with basal ganglia lesions who attended at the Pediatric Neurology Unit at AlAzhar University Hospitals during a period of one year from the beginning of November 2014 to the end of October 2015. All patients below the age of 18 years were included in the study. A written consent was taken from parents of the patients or their caregivers before inclusion in the study. The study was approved by the ethics committee of faculty of medicine, Al Azhar University, Cairo, Egypt. Inclusion criteria were children with neurological disorders diagnosed to have isolated ganglionic lesions (IG) or combined ganglionic and paraganglionic lesions (CGP) according to MRI findings. Exclusion criteria were children who had basal ganglionic tumors or post traumatic basal ganglia lesions and children. All cases were subjected to the following procedures:

1. Detailed medical and neurological history, the history taking included the following:

- Personal history

- Prenatal, natal and postnatal history

- Family pedigree construction to detect any hereditary disorders

- Developmental history

2. Full general and neurological examination

3. Neuropsychiatric assessment using StanfordBinet Intelligence Scale: Fourth Edition. Types of cognitive impairment subdivided into four categories: mild intellectual disability (IQ 50 to 70), moderate intellectual disability (IQ 35 to 49), severe intellectual disability (IQ 20 to 34), and profound intellectual disability (IQ less than 20).

4. Laboratory assessment including:

- Routine laboratory investigation: complete blood count, liver function tests, renal function tests, ESR and random blood glucose.

- Specific laboratory investigations: such as in cases suggesting ischemic stroke (ANA, anti cardiolipin, INR), in cases suggesting Wilsons disease (serum ceruloplasmin, serum and urinary copper), in cases suggesting infectious diseases (CSF analysis \& culture). cases suggesting Wilsons disease, echocardiography and ECG in cases suggesting ischemic stroke.

6. Slit lamp examination in cases suggesting Wilsons disease.

\section{Statistical Analysis}

All data were collected, presented and analyzed by using an appropriate statistical package program (statistical package for social science) (SPSS), version 20. Qualitative data were presented by number and percentage.

\section{Resullts}

The included patients were classified according to MRI into two groups; ganglionic group that included patients with isolated basal ganglionic lesions $(n=23)$ and paraganglionic group that included patients with basal ganglionic as well as paraganglionic lesions $(n=11)$

The study showed the demographic characteristics of both studied groups. The mean age of ganglionic group was significantly higher than paraganglionic group (9.0 years versus 5.7 years, respectively). The frequency of male patients was slightly higher than the female patients in both groups without significant difference (13 (56.5\%) versus 6 (43.5\%) and $10(54.5 \%)$ versus5 $(45.5 \%)$, in ganglionic and paraganglionic groups, respectively).

Table 1. Age and sex distribution of patients.

\begin{tabular}{|l|l|l|l|}
\hline Variables & \multicolumn{1}{l}{$\begin{array}{l}\text { Total population } \\
(\mathbf{n}=\mathbf{3 4})\end{array}$} & $\begin{array}{l}\text { IG } \\
(\mathbf{n}=\mathbf{2 3})\end{array}$ & $\begin{array}{l}\text { CGP } \\
(\mathbf{n}=\mathbf{1 1})\end{array}$ \\
\hline \multicolumn{3}{|l|}{ Age (years) } \\
\hline Mean \pm SD & $8.0 \pm 4.9$ & $9.0 \pm 4.0$ & $5.7 \pm 4.0$ \\
\hline Range & 217 & 217 & 216 \\
\hline Gender, n (\%) & $13(56.5 \%)$ & $6(54.5 \%)$ \\
\hline Male & $19(55.9 \%)$ & $10(43.5 \%)$ & $5(45.5 \%)$ \\
\hline Female & $15(44.1 \%)$ &
\end{tabular}

Regarding isolated ganglionic group and according to brain MRI imaging; bilateral cases were 16 (69.70\%), unilateral cases located in the following sites; in the Putamen were $2(8.7 \%)$ cases, Caudate and putamen was $1(4.3 \%)$, Caudate and lentiform nucleolus was $1(4.3 \%)$, Caudate were $2(8.7 \%)$ and Globus pallidus was $1(4.3 \%)$

\section{Other imaging studies: such as abdominal ultrasound in}




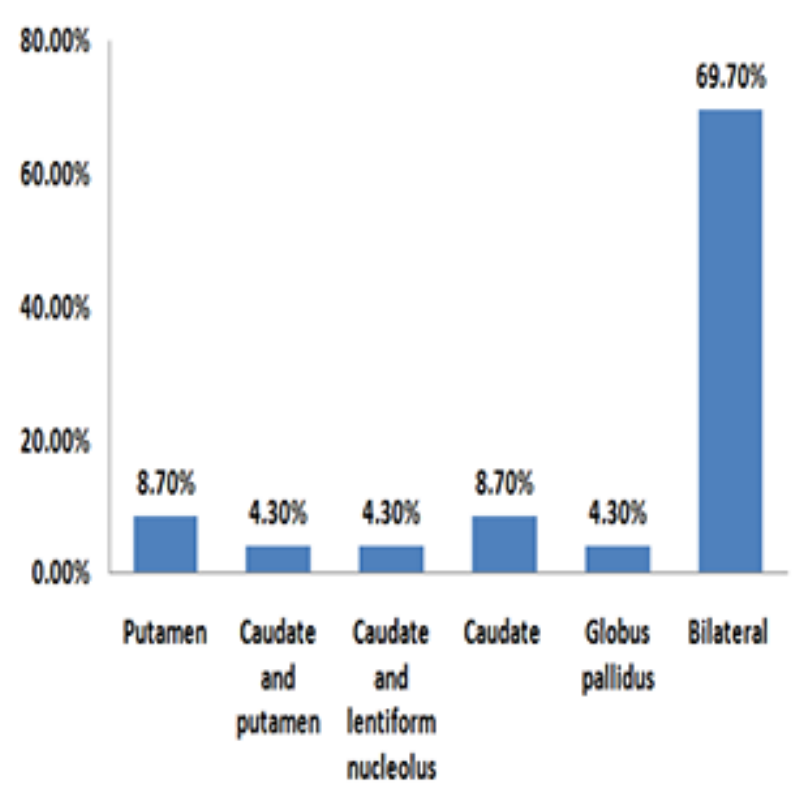

Figure (1): Site of lesions according to MRI among (IG) studied group.

Regarding combined ganglionic and para ganglionic group and According to brain MRI imaging; cases located in the following sites; in the Temproparital were $2(18.2 \%)$ cases, Temporal were $2(18.2 \%)$, Temprooccipital was $1(9.1 \%)$, Occipital were $2(18.2 \%)$, Cortical brain atrophy was 1 $(9.1 \%)$, Periventricular leukomalacia was $1(9.1 \%)$, Parital was $1(9.1 \%)$ and Pontine was $1(9.1 \%)$

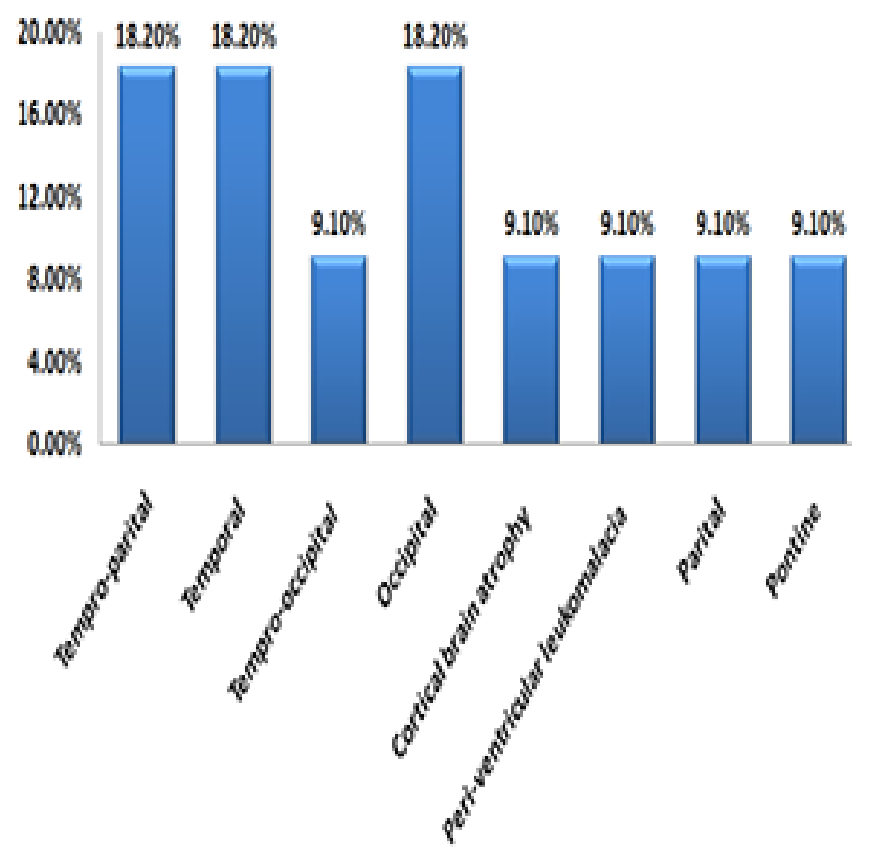

Figure (2): Site of lesions according to MRI among (CGP) studied group.
Acute ischemic stroke was the most frequent cause, which was found in $12(35.3 \%)$ cases, followed by $10(29.4 \%)$ had metabolic and infectious causes, and lastly $2(5.9 \%)$ had toxic causes. The incidence of toxic causes (CO poisoning) was significantly higher among ganglionic group compared to paraganglionic group ( $8.7 \%$ versus $0.0 \%$, respectively).

\begin{tabular}{|l|l|l|l|}
\hline Variables & $\begin{array}{l}\text { Total } \\
\text { population } \\
(\mathbf{n = 3 4 )}\end{array}$ & $\begin{array}{l}\text { IG } \\
(\mathbf{n}=\mathbf{2 3})\end{array}$ & $\begin{array}{l}\text { CGP } \\
(\mathbf{n = 1 1})\end{array}$ \\
\hline Causes, n (\%) & \multicolumn{2}{|l|}{} \\
\hline Ischemic & $12(35.3 \%)$ & $8(34.8 \%)$ & $4(36.4 \%)$ \\
\hline Infectious & $10(29.4 \%)$ & $6(26.1 \%)$ & $4(36.4 \%)$ \\
\hline Metabolic & $10(29.4 \%)$ & $7(30.4 \%)$ & $3(27.2 \%)$ \\
\hline Toxic & $2(5.9 \%)$ & $2(8.7 \%)$ & $0(0.0 \%)$ \\
\hline
\end{tabular}

Table (2): Etiological causes in the studied children.

The incidence of cognitive dysfunction, and abnormal movements were higher among metabolic cases $(100.0 \%$, and $33.3 \%$, respectively), hemiparesis was higher among ischemic cases (100.0\%), and seizures and disturbed levels of consciousness were higher among infectious cases $(100.0 \%$ and $100.0 \%$, respectively).In infectious cases, three cases $(75.0 \%)$ show pancytopenia, three cases $(75.0 \%)$ shows liver dysfunction, two cases $(50.0 \%)$ shows elevated ESR, and two cases $(50.0 \%)$ shows leukocytosis and elevated protein levels in CSF. In metabolic cases, two cases (66.7\%) show pancytopenia, one case (33.3\%) show liver dysfunction, inceased serum ceruloplasmin, decreased serum copper and increased urinary copper (Wilson disease), one case $(14.3 \%)$ shows hypoglycemia, and one case (14.3\%) shows hyponatremia (central pontine myelinolysis). 


\begin{tabular}{|c|c|c|c|c|c|}
\hline \multicolumn{2}{|c|}{ Variables } & $\begin{array}{l}\text { Ischemic } \\
(\mathrm{n}=8)\end{array}$ & Infectious (n=6) & Metabolic (n=7) & Toxic $(n=2)$ \\
\hline \multicolumn{6}{|c|}{ Clinical evaluation: } \\
\hline \multicolumn{2}{|c|}{ Cognitive dysfunction } & $1(12.5 \%)$ & $1(16.7 \%)$ & $4(57.1 \%)$ & $0(0.0 \%)$ \\
\hline \multicolumn{2}{|c|}{ Hemiparesis } & $6(75.0 \%)$ & $1(16.7 \%)$ & $0(0.0 \%)$ & $0(0.0 \%)$ \\
\hline \multicolumn{2}{|c|}{ Abnormal movements } & $0(0.0 \%)$ & $0(0.0 \%)$ & $7(100.0 \%)$ & $0(0.0 \%)$ \\
\hline \multicolumn{2}{|c|}{ Seizures } & $1(12.5 \%)$ & $6(100.0 \%)$ & $1(14.3 \%)$ & $2(100.0 \%)$ \\
\hline \multicolumn{2}{|c|}{$\begin{array}{l}\text { Disturbed level of } \\
\text { consciousness }\end{array}$} & $1(12.5 \%)$ & $2(33.3 \%)$ & $0(0.0 \%)$ & $2(100.0 \%)$ \\
\hline \multicolumn{2}{|c|}{ Rigidity } & $1(12.5 \%)$ & $0(0.0 \%)$ & $3(42.9 \%)$ & $0(0.0 \%)$ \\
\hline \multicolumn{6}{|c|}{ Laboratory evaluation: } \\
\hline \multicolumn{2}{|c|}{ Pancytopenia } & $0(0.0 \%)$ & $2(33.3 \%)$ & $4(57.1 \%)$ & $0(0.0 \%)$ \\
\hline \multicolumn{2}{|c|}{ Liver dysfunction } & $0(0.0 \%)$ & $3(50.0 \%)$ & $5(71.4 \%)$ & $0(0.0 \%)$ \\
\hline \multicolumn{2}{|c|}{ Renal dysfunction } & $0(0.0 \%)$ & $0(0.0 \%)$ & $0(0.0 \%)$ & $0(0.0 \%)$ \\
\hline \multicolumn{2}{|c|}{ Elevated ESR } & $4(50.0 \%)$ & $2(33.3 \%)$ & $3(42.9 \%)$ & $0(0.0 \%)$ \\
\hline \multicolumn{2}{|c|}{ Hyperglycemia } & $1(12.5 \%)$ & $0(0.0 \%)$ & $0(0.0 \%)$ & $0(0.0 \%)$ \\
\hline \multicolumn{2}{|c|}{ Hypoglycemia } & $0(0.0 \%)$ & $0(0.0 \%)$ & $1(14.3 \%)$ & $0(0.0 \%)$ \\
\hline \multicolumn{2}{|c|}{ Dyslipidemia } & $2(25.0 \%)$ & $0(0.0 \%)$ & $0(0.0 \%)$ & $0(0.0 \%)$ \\
\hline \multicolumn{2}{|c|}{ Positive ANA } & $0(0.0 \%)$ & & & \\
\hline \multicolumn{2}{|c|}{ Positive anticardiolipin } & $0(0.0 \%)$ & & & \\
\hline \multicolumn{2}{|c|}{ Elevated INR } & $0(0.0 \%)$ & & & \\
\hline \multicolumn{2}{|c|}{ Leukocytosis (CSF) } & & $2(33.3 \%)$ & & \\
\hline \multicolumn{2}{|c|}{ Elevated protein (CSF) } & & $3(50.0 \%)$ & & \\
\hline \multicolumn{2}{|c|}{$\begin{array}{l}\text { Increased serum } \\
\text { ceruloplasmin }\end{array}$} & & & $4(57.1 \%)$ & \\
\hline \multicolumn{2}{|c|}{ Decreased serum copper } & & & $4(57.1 \%)$ & \\
\hline \multicolumn{2}{|c|}{ Increased urinary copper } & & & $4(57.1 \%)$ & \\
\hline \multicolumn{2}{|c|}{ Hyponatremia } & & & $0(0.0 \%)$ & \\
\hline \multicolumn{2}{|c|}{$\begin{array}{l}\text { Hypoparath } \\
\text { yroidism }\end{array}$} & & & $1(14.3 \%)$ & \\
\hline \multicolumn{6}{|c|}{ Imaging evaluation: } \\
\hline $\mathrm{U} / \mathrm{S}($ & cirrhosis) & $0(0.0 \%)$ & $0(0.0 \%)$ & $1(14.3 \%)$ & $0(0.0 \%)$ \\
\hline $\begin{array}{l}\text { plain } \\
\text { costo }\end{array}$ & $\begin{array}{l}\text { ys (obliterated } \\
\text { nic angle) }\end{array}$ & $1(12.5 \%)$ & $0(0.0 \%)$ & $0(0.0 \%)$ & $0(0.0 \%)$ \\
\hline Abno & $1 \mathrm{ECG}$ & $1(12.5 \%)$ & $0(0.0 \%)$ & $0(0.0 \%)$ & $0(0.0 \%)$ \\
\hline Echo & tral regurgitation) & $1(12.5 \%)$ & $0(0.0 \%)$ & $0(0.0 \%)$ & $0(0.0 \%)$ \\
\hline MRI & Ischemic infarction & $8(100.0 \%)$ & & & \\
\hline & Encephalitis & & $6(100.0 \%)$ & & \\
\hline & Putamen & $2(25.0 \%)$ & $0(0.0 \%)$ & $0(0.0 \%)$ & $0(0.0 \%)$ \\
\hline & \begin{tabular}{|l|}
$\begin{array}{l}\text { Caudate and } \\
\text { putamen }\end{array}$ \\
\end{tabular} & $1(12.5 \%)$ & $0(0.0 \%)$ & $0(0.0 \%)$ & $0(0.0 \%)$ \\
\hline & Caudate & $2(25.0 \%)$ & $1(16.7 \%)$ & $0(0.0 \%)$ & $0(0.0 \%)$ \\
\hline & Globus pallidus & $1(12.5 \%)$ & $0(0.0 \%)$ & $0(0.0 \%)$ & $0(0.0 \%)$ \\
\hline & Bilateral & $2(25.0 \%)$ & $5(83.3 \%)$ & $7(100.0 \%)$ & $2(100.0 \%)$ \\
\hline
\end{tabular}

Table (3): Relationship between etiological factors and clinical, laboratory and imaging findings in studied (IG) children. 
A): Relationship between etiological factors and clinical evaluation in studied children.

\begin{tabular}{|l|l|l|l|}
\hline Variables & $\begin{array}{l}\text { Ischemic } \\
(\mathbf{n}=\mathbf{4})\end{array}$ & $\begin{array}{l}\text { Infectious } \\
(\mathbf{n = 4 )}\end{array}$ & $\begin{array}{l}\text { Metabolic } \\
(\mathbf{n}=3)\end{array}$ \\
\hline $\begin{array}{l}\text { Cognitive } \\
\text { dysfunction }\end{array}$ & $1(25.0 \%)$ & $2(50.0 \%)$ & $3(100.0 \%)$ \\
\hline Hemiparesis & $4(100.0 \%)$ & $0(0.0 \%)$ & $1(33.3 \%)$ \\
\hline Quadriparesis & $0(0.0 \%)$ & $0(0.0 \%)$ & $1(33.3 \%)$ \\
\hline $\begin{array}{l}\text { Abnormal } \\
\text { movements }\end{array}$ & $0(0.0 \%)$ & $0(0.0 \%)$ & $1(33.3 \%)$ \\
\hline Seizures & $1(25.0 \%)$ & $4(100.0 \%)$ & $2(66.7 \%)$ \\
\hline $\begin{array}{l}\text { Disturbed } \\
\text { level of } \\
\text { consciousness }\end{array}$ & $3(75.0 \%)$ & $4(100.0 \%)$ & $2(66.7 \%)$ \\
\hline Rigidity & $0(0.0 \%)$ & $0(0.0 \%)$ & $0(0.0 \%)$ \\
\hline
\end{tabular}

B): Relationship between etiological factors and laboratory evaluation in studied children.

\begin{tabular}{|c|c|c|c|}
\hline Variables & $\begin{array}{l}\text { Ischemic } \\
(n=4)\end{array}$ & $\begin{array}{l}\text { Infectious } \\
(n=4)\end{array}$ & $\begin{array}{l}\text { Metabolic } \\
(\mathrm{n}=\mathbf{3})\end{array}$ \\
\hline Pancytopenia & $0(0.0 \%)$ & $3(75.0 \%)$ & $2(66.7 \%)$ \\
\hline Liver dysfunction & $0(0.0 \%)$ & $3(75.0 \%)$ & $1(33.3 \%)$ \\
\hline Renal dysfunction & $0(0.0 \%)$ & $0(0.0 \%)$ & $2(66.7 \%)$ \\
\hline Elevated ESR & $125.0 \%)$ & $2(50.0 \%)$ & $3(100.0 \%)$ \\
\hline Hyperglycemia & $0(0.0 \%)$ & $0(0.0 \%)$ & $0(0.0 \%)$ \\
\hline Hypoglycemia & $0(0.0 \%)$ & $0(0.0 \%)$ & $1(33.3 \%)$ \\
\hline Dyslipidemia & $0(0.0 \%)$ & $0(0.0 \%)$ & $0(0.0 \%)$ \\
\hline Positive ANA & $0(0.0 \%)$ & & \\
\hline $\begin{array}{l}\text { Positive } \\
\text { anticardiolipin }\end{array}$ & $0(0.0 \%)$ & & \\
\hline Elevated INR & $0(0.0 \%)$ & & \\
\hline Leukocytosis (CSF) & & $2(50.0 \%)$ & \\
\hline $\begin{array}{l}\text { Elevated protein } \\
(\mathrm{CSF})\end{array}$ & & $2(50.0 \%)$ & \\
\hline $\begin{array}{l}\text { Increased serum } \\
\text { ceruloplasmin }\end{array}$ & & & $1(33.3 \%)$ \\
\hline $\begin{array}{l}\text { Decreased serum } \\
\text { copper }\end{array}$ & & & $1(33.3 \%)$ \\
\hline $\begin{array}{l}\text { Increased urinary } \\
\text { copper }\end{array}$ & & & $1(33.3 \%)$ \\
\hline Hyponatremia & & & $1(33.3 \%)$ \\
\hline Hypoparathyroidism & & & $0(0.0 \%)$ \\
\hline
\end{tabular}

C): Relationship between etiological factors and MRI evaluation in studied children.

\begin{tabular}{|l|l|l|l|}
\hline Variables & $\begin{array}{l}\text { Ischemic } \\
(\mathbf{n = 4})\end{array}$ & $\begin{array}{l}\text { Infectious } \\
(\mathbf{n}=4)\end{array}$ & $\begin{array}{l}\text { Metabolic } \\
(\mathbf{n}=3)\end{array}$ \\
\hline $\begin{array}{l}\text { Ischemic } \\
\text { infarction }\end{array}$ & $4(100.0 \%)$ & & \\
\hline Encephalitis & & $4(100.0 \%)$ & \\
\hline Temproparital & $2(50.0 \%)$ & $0(0.0 \%)$ & $0(0.0 \%)$ \\
\hline Temporal & $1(25.0 \%)$ & $1(25.0 \%)$ & $0(0.0 \%)$ \\
\hline Temprooccipital & $1(25.0 \%)$ & $0(0.0 \%)$ & $0(0.0 \%)$ \\
\hline Occipital & $0(0.0 \%)$ & $2(50.0 \%)$ & $0(0.0 \%)$ \\
\hline $\begin{array}{l}\text { Cortical brain } \\
\text { atrophy }\end{array}$ & $0(0.0 \%)$ & $1(25.0 \%)$ & $0(0.0 \%)$ \\
\hline $\begin{array}{l}\text { Periventricular } \\
\text { leukomalacia }\end{array}$ & $0(0.0 \%)$ & $0(0.0 \%)$ & $1(33.3 \%)$ \\
\hline Parital & $0(0.0 \%)$ & $0(0.0 \%)$ & $1(33.3 \%)$ \\
\hline Pontine & $0(0.0 \%)$ & $0(0.0 \%)$ & $1(33.3 \%)$ \\
\hline
\end{tabular}

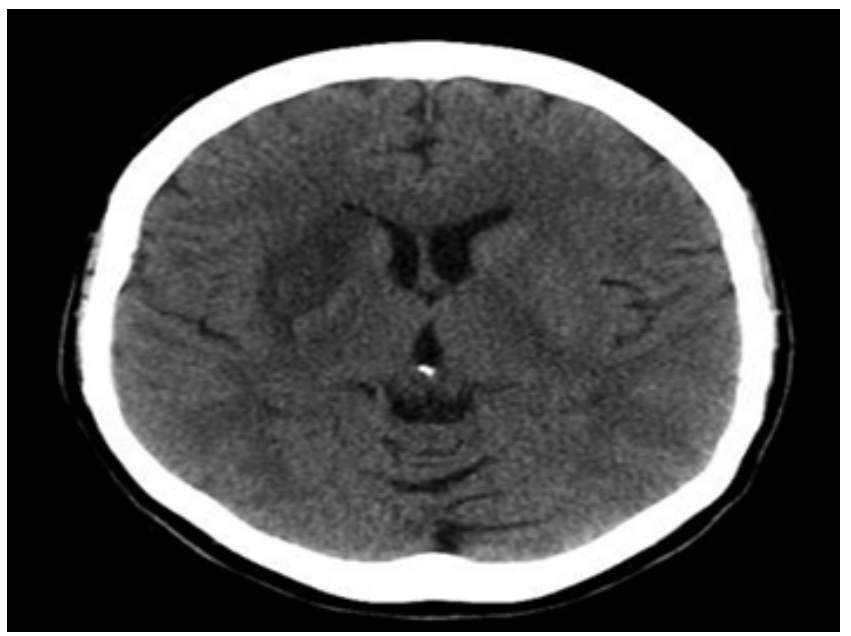

Figure (2): 7 years old male presented with left sided hemiparesis, Axial non contrast computed tomography demonstrates diffuse hypodensity in the right lentiform nucleus, with mass effect upon the frontal horn of the right lateral ventricle (ischemic stroke)

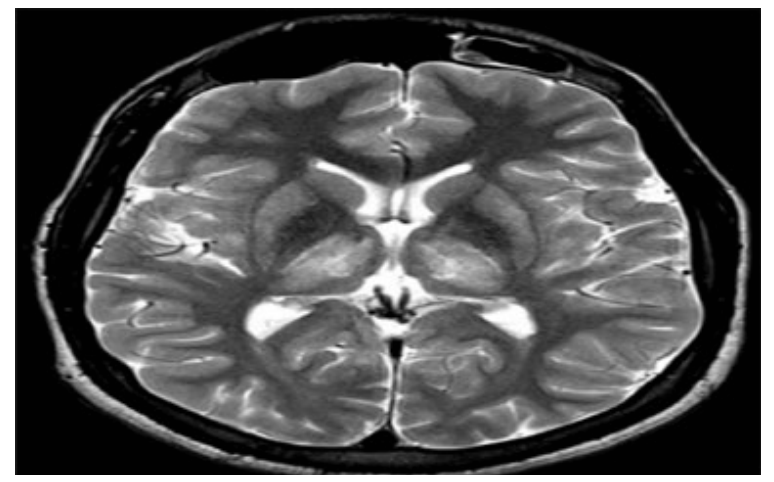

Figure (3): 13 years old female presented with disturbed level of consciousness and abnormal movement (dystonia like), MRI of the brain revealed bilateral high Signal intensity affecting bilateral thalami and putamen on T2weighted axial MRI (Wilson disease) 


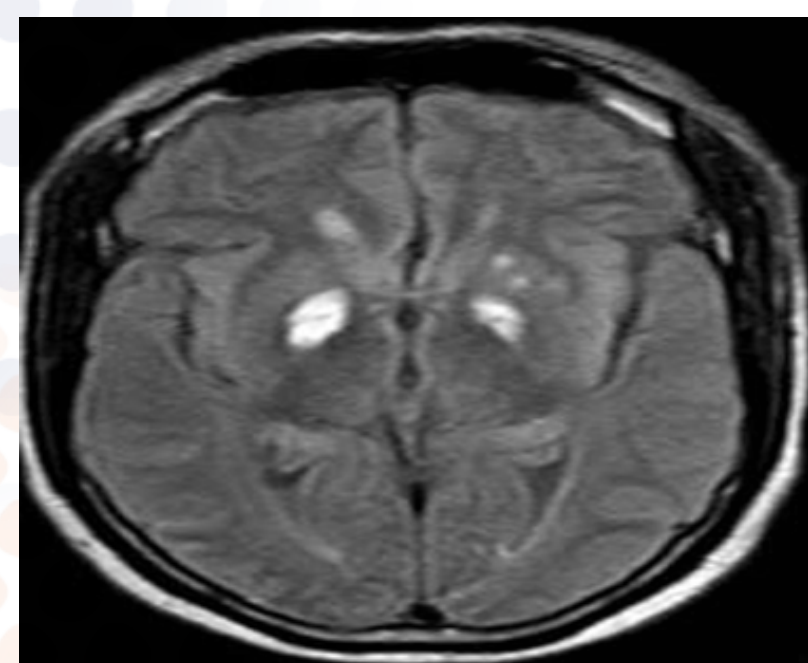

Figure (4): 17 years old female presented with disturbed level of consciousness and Generalized seizures, MRI of the brain revealed bilateral high Signal intensity affecting basal ganglia on flair weighted axial MRI (CO poisoning)

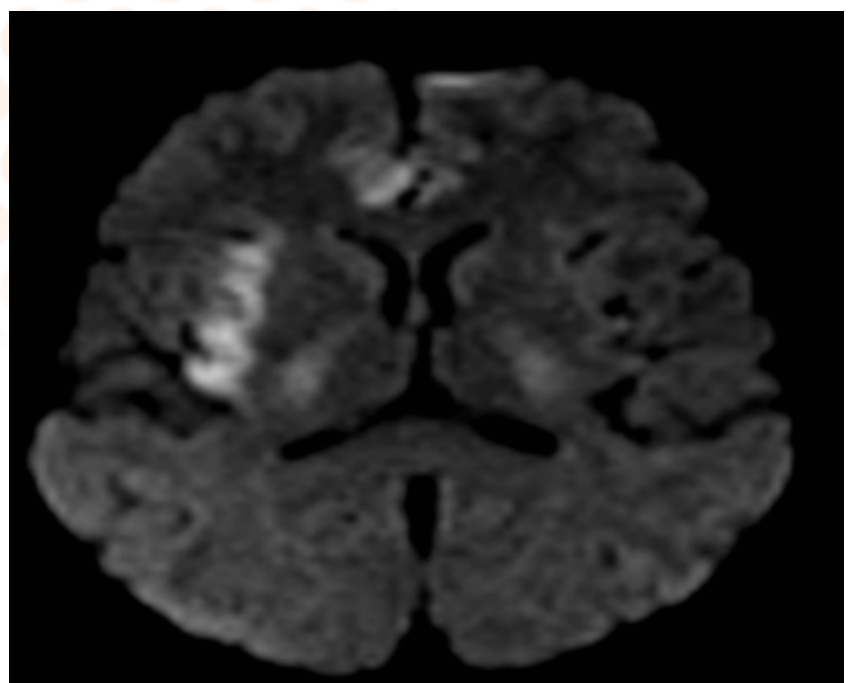

Figure (5): 16 years old male presented with disturbed level of consciousness and Generalized seizures, MRI of the brain revealed bilateral basal ganglia restricted diffusion on DWI (encephalitis)

\section{Discussion}

The basal ganglia are a site of high ATP production and thus require a relatively disproportionate increased blood supply. Consequently, bilateral basal ganglia alterations are often observed in pathological processes affecting energy metabolism. A complete differential diagnosis of systemic and metabolic diseases would be exhaustive; therefore, understanding of the underlying pathology and imaging findings is critical for final diagnosis, treatment, and prognosis [4].

This study included 23 patients who were analysed clinically and biochemically. Mean age was $9.0 \pm 4.0$ years. The disorders of basal ganglia occur most commonly in school aged children from 6.0 to 12.0 years [5], and this agree with the results of the present study. In an epidemiological study in the city of Kolkata, India, the commonest age group was 1019 years [6]. Male are more than the females in the present study, 13 $(56.5 \%)$ cases were males and $10(43.5 \%)$ cases were females. Similar observation was also made by some other researchers $[7,8,9]$. This may be explained by a male child being brought to the hospital for medical attention than the female especially in the developing countries which is considered as a part of social habits.

In the present study, acute ischemic stroke was the most frequent cause, which was found in $8(34.8 \%)$ cases, followed by $7(30.4 \%)$ had metabolic causes, $6(26.1 \%)$ had infectious causes, and lastly $2(8.7 \%)$ had toxic causes.

Both acute and progressive disorders can result in bilateral symmetrical basal ganglia alterations. Our results are in agreement with Williams et al. (2012) they reported that primary acute causes include hypoxicischemic injury, infection, autoimmune disorders, and toxic encephalopathies. Subacute or progressive pathologies are usually neurodegenerative and/ or metabolic in nature [3].

Ischemic stroke was most frequent cause in this study as rheumatic heart disease in Egypt is common, since the major risk factors for rheumatic fever include poverty, overcrowding, and poor access to medical services, this is similar to community data reported from Australian aborigines, that suggest a much higher prevalence of rheumatic heart disease in children around 15 years of age [10,11].

The incidence of cognitive dysfunction, abnormal movements, and rigidity were higher among metabolic cases $(57.1 \%$, $100.0 \%$, and $42.9 \%$, respectively), hemiparesis was higher among ischemic cases $(75.0 \%)$, and seizures were higher among infectious and toxic cases $(100.0 \%$ and $100.0 \%$, respectively). In infectious cases, two (33.3\%) showed pancytopenia, three $(50.0 \%)$ showed liver dysfunction, two $(33.3 \%)$ showed elevated ESR, and two (33.3\%) showed leukocytosis in CSF and three (50.0\%) showed elevated protein levels in CSF. In metabolic cases, $57.1 \%$ of the patients showed pancytopenia, five $(71.4 \%)$ showed liver dysfunction ( 4 cases of Wilson disease and 1 case of liver cirrhosis), four (57.1\%) showed increased serum ceruloplasmin, decreased serum copper and increased urinary copper (Wilson disease), one $(14.3 \%)$ showed hypoglycemia, and one (14.3\%) showed hyperparathyroidism.

Previous studies also reported that Wilson disease or hepatolenticular degeneration involves an excessive accumulation of copper. Copper accumulates primarily in the liver and brain, resulting in mainly hepatic and neurological sequela. On MRI, the basal ganglia, specifically the putamina, caudate nuclei, and globi pallidi, are hyperintense on T1 weighted and T2 weighted images [12-16].

The basal ganglia may be affected in patients with liver dysfunction. Most patients have a history of chronic cirrhosis 
resulting in nitrogenous waste products crossing the blood brain barrier and causing longterm toxic brain damage [17].

Hypoglycemia may produce similar injury to hypoxia as lack of glucose may have similar effect on metabolism as lack of oxygen. Also affected structures are the same: basal ganglia, cortex, substantia nigra, and hippocampus. The lesions in basal ganglia are T2 and DWI hyperintense. However, in hypoglycemic coma survivors the signal intensity is T1 hyperintense and T2 hypointense [18]. Hypoparathyroidism is the most common cause of bilateral symmetric calcification of the basal ganglia [19].

\section{Conclusions}

Unilateral basal ganglionic lesions occurred mostly in ischemic stroke while bilateral basal ganglionic lesions occurred mostly in metabolic disorders.

\section{References}

1. Stocco A, Lebiere C, Anderson R (2011) Conditional Routing of Information to the Cortex: A Model of the Basal Ganglia's Role in Cognitive Coordination. Psychol Rev. 117(2): 541-574.

2. Bailey R (2010) Divisions of the Brain. Arch Ret. 20(10): 11-30.

3. Williams K, Thomson D, Seto I, StaR (2012) age groups for pediatric trials. Pediatrics129 (Suppl3): S153-S160.

4. Lanciego JL, Gonzalo N, Castle M, Sanchez Escobar C, Aymerich MS, Obeso JA (2004) Thalamic innervation of striatal and subthalamic neurons projecting to the rat entopeduncular nucleus. Eur. J. Neurosci. 19: 1267-1277.

5. Dooley J (2006) Tic Disorders in Childhood. Semin Pediatr Neurol. 13(4): 231-242.

6. Das S, Banerjee T, Roy T, Raut D, Chaudhuri A, Hazra A (2009) Prevalence of Essential Tremor in the City of Kolkata, India: A HousetoHouse Survey, Eur J Neurol. 16(7): 801-807.

7. Jin R, Zheng R, Huang W, Xu H, Shao B, Chen H, Feng L (2005) Epidemiological survey of Tourette syndrome in children and adolescents in Wenzhou of PR China. Eur J Epidemiol. 20(11): 925-927.

8. Leckman J, Bloch N, Scahill L, King R (2006) Tourette Syndrome: The Self Under Siege. J Child Neurol. 21(8): 642-649.

9. Scahill L, Bitsko R, Visser S, Blumberg S (2009) Prevalence of diagnosed tourette syndrome in persons aged 617 yearsUnited States, 2007. Morbidity and Mortality Weekly Report. 58(21): 581-585.

10. Carapetis JR, Steer AC, Mulholland E, Weber M (2005) The global burden of group A streptococcal diseases. The Lancet Infect Dis. 5: 685-694.

11. Carapetis JR, Currie BJ, Mathews JD (2000) Cumulative incidence of rheumatic fever in an endemic region: A guide to the susceptibility of the population? Epidemiol Infect, 124: 239-244.

12. Tissières P, Chevret L, Debray D, Devictor D (2003)
Fulminant Wilson's disease in children: appraisal of a critical diagnosis. Pediatr Crit Care Med. 4: 338-343.

13. Yüce A, Koçak N, Demir H, Gürakan F, Ozen H, Saltik I, Ozcay F (2003) Evaluation of diagnostic parameters of Wilson's disease in childhood. Indian J Gastroenterol. 22: 4-6.

14. Dhawan A, Taylor R, Cheeseman P, De Silva P, Katsiyiannakis L, Mieli-Vergani G (2005) Wilson's disease in children: 37year experience and revised King's score for liver transplantation. Liver Transpl 11: 441-448.

15. Marcellini M, Di Ciommo V, Callea F, Devito R, Comparcola D, Sartorelli M, Carelli F, Nobili V (2005) Treatment of Wilson's disease with zinc from the time of diagnosis in pediatric patients: a singlehospital, 10year followup study. J Lab Clin Med 145: 139-143.

16. ArnonR, Calderon J, Schilsky M,Emre S, ShneiderB(2007) Wilson disease in children: serum aminotransferases and urinary copper on triethylene tetramine dihydrochloride (trientine) treatment. J Pediatr Gastroenterol Nutr 44: 596-602.

17. Hegde A, Mohan S, Lath N, Lim C (2011) Differential diagnosis for bilateral abnormalities of the basal ganglia and thalamus. Radiographic. 31: 5-30.

18. BekiesinskaFigatowska M, Mierzewska H, Jurkiewicz E (2013) Basal ganglia lesions in children and adults. Eur J Radiol. 82(5): 837-849.

19. Zuccoli G, Yannes M, Nardone R, Bailey A, Goldstein A (2015) Bilateral symmetrical basal ganglia and thalamic lesions in children: an update (2015). Neuroradiol. 57(10): 973-989.

Copyright: (C2020 Hamada Ibrahim Zehry. This is an open-access article distributed under the terms of the Creative Commons Attribution License, which permits unrestricted use, distribution, and reproduction in any medium, provided the original author and source are credited. 